\title{
SMR
}

\section{High MMP-1, MMP-2, and MMP-9 protein levels in osteoarthritis}

\author{
G.Q. Zeng, A.B. Chen, W. Li, J.H. Song and C.Y. Gao \\ Department of Trauma and Orthopedics, The 425th Hospital of PLA, \\ Sanya, Hainan China \\ Corresponding author: A.B. Chen \\ E-mail: chenaibao401@163.com
}

Genet. Mol. Res. 14 (4): 14811-14822 (2015)

Received June 6, 2015

Accepted September 28, 2015

Published November 18, 2015

DOI http://dx.doi.org/10.4238/2015.November.18.46

\begin{abstract}
Our study examined the relationship between the expression of matrix metalloproteinases (MMP)-1, MMP-2, and MMP-9 proteins and the pathogenesis of osteoarthritis (OA). We employed rigorous inclusion and exclusion criteria in computer-based bibliographic databases to extract published studies relevant to this investigation. The STATA 12.0 software was used for the statistical analyses. A total of 1408 studies were initially searched, and 10 studies with 458 OA patients and 295 healthy controls were included in this meta-analysis. The meta-analysis results suggested that the protein levels of MMP-1, MMP-2, and MMP-9 were higher in patients with OA than those in the control group. A subgroup analysis according to ethnicity showed that the protein levels of MMP-1 and MMP-2 were higher in Asian patients with OA than in controls. Caucasians showed no statistically significant differences in protein expression of MMP1 and MMP-2 between the OA patient group and the control group. Interestingly, the protein levels of MMP-9 in patients with OA were higher than those in the control group in both Asians and Caucasians. A sample-source analysis suggested that the serum levels of MMP-2 and MMP-9 proteins were higher in patients with OA than in controls, while MMP-1 and MMP-9 protein expressions were higher in the
\end{abstract}


synovial joint fluid of patients with OA than in controls. In conclusion, our meta-analysis results suggested that the increased expression of MMP-1, MMP-2, and MMP-9 proteins might be associated with the pathogenesis of OA.

Key words: Osteoarthritis; MMP-1; MMP-2; MMP-9; Gelatinase; Matrix metalloproteinases

\section{INTRODUCTION}

Osteoarthritis (OA), the most prevalent form of chronic joint disorders, is a process of deterioration and ongoing biological breakdown of articular cartilage in synovial joint tissues, including subchondral bone, periarticular muscles, synovium, peripheral nerves, joint capsular tissues, and ligaments (Dreier, 2010; Lane et al., 2011). OA may occur in any joint, but it is most commonly seen in the hands, hips, facet joints, and feet. OA can cause pain, swelling, stiffness, muscle weakness, along with joint instability, all of which may give rise to a gradual loss of physical function and poor quality of life (Bennell and Hinman, 2011). Generally, OA has become a leading health issue in the aging population, with approximately 10 to $20 \%$ of all people over 60 presenting symptomatic OA and with more women affected than men after 50 (Bijlsma et al., 2011; Ekman et al., 2014). The most recognized risk factors for OA are gender, advancing age, obesity, prior joint injury, genetic predisposition, and mechanical factors, such as abnormal joint shape (Blagojevic et al., 2010). Currently, no curative therapies that effectively prevent and treat OA exist, and the clinical management of OA mainly involves the control of pain and inflammation and procedures to improve joint function (Xu et al., 2010). Recently, matrix metalloproteinases (MMPs), especially MMP-1, MMP-2, and MMP-9, have emerged as the leading candidates for involvement in the disease progression of OA (Murphy and Nagase, 2008).

MMPs, a large family of zinc-dependent proteolytic enzymes, are involved in the degradation of their target proteins through the cleavage of internal peptide bonds (Bourboulia and Stetler-Stevenson, 2010). The MMP family consists of at least 28 members thus far, and all amino acid sequences of MMPs have two conserved domains, a catalytic domain and a prodomain, which are important for their substrate specificity. All of the members of the MMP family have broad substrate specificities, but their main substrates include gelatinases, collagenases, matrilysins, stromelysins, membrane-type MMPs, and metalloelastase (Hemmann et al., 2007). Generally, MMPs can degrade any extracellular matrix component, including proteoglycans, vitronectin, fibronectin, laminin, and collagens. From a development and disease perspective, MMPs are crucial during embryonic growth and reproduction, and they play a major role in tumor growth and metastasis (Salgame, 2011; Lukaszewicz-Zajac et al., 2014). MMP-1, MMP-2, and MMP-9 are key members of the MMP family. MMP-1, which is a collagenase, plays a crucial role in cancer progress and metastasis (Lepetsos et al., 2014). MMP-2, which is localized in cardiomyocytes, can degrade type-IV collagen and other bioactive molecules, and it is overexpressed in head and neck squamous cell carcinoma during cancer invasion and metastasis (Hughes and Schulz, 2014). MMP-9, which is a gelatinase like MMP-2, is the most complex member of the MMP family with its proteolytic activity against type-IV collagen and its upregulated expression in multiple types of human cancer, including 
gastric cancer, breast cancer, and esophageal cancer (De Groef et al., 2014). Recently, a variety of studies have examined the relationship of the expression of MMP-1, MMP-2, and MMP-9 proteins and the pathogenesis of OA (Jackson et al., 2014; Tio et al., 2014). MMP-1, MMP2, and MMP-9 protein expression levels have been reported to be either correlated with OA or not related at all to OA (Heard et al., 2012; Xue et al., 2014). We therefore conducted a meta-analysis to examine the relationship of MMP-1, MMP-2, and MMP-9 expression and the pathogenesis of OA.

\section{MATERIAL AND METHODS}

\section{Literature search}

In order to capture all published studies relevant to MMP-1, MMP-2, and MMP-9 expression in the pathogenesis of $\mathrm{OA}$, we performed a comprehensive electronic database search of the PubMed, EBSCO, Ovid, Web of Science, SpringerLink, Wiley, China BioMedicine (CBM), China National Knowledge Infrastructure (CNKI), and Wanfang databases (last updated search in September 2014), and we manually retrieved related data. Our sensitive search strategy employed the following search terms: ("matrix metalloproteinases" or "MMP") and ("osteoarthritis", "osteoarthritides", "osteoarthrosis", "osteoarthroses", "orthritides", "orthritis", "osteoarthrosis deformans", or "OA") without a language bias. The bibliographies of related papers were manually examined for potential relevant articles.

\section{Inclusion and exclusion criteria}

Full articles were retrieved and evaluated by reading the abstract for their suitability based on the following inclusion criteria: 1) clinical-cohort study themes should focus on correlations among MMP-1, MMP-2, MMP-9, and OA; 2) all patients should be clinically diagnosed with $\mathrm{OA} ; 3$ ) the detection method should be enzyme-linked immunosorbent assays; 4) the data should be complete; and 5) they should be in Chinese or English. Only the complete or latest study was included after careful re-examination when extracted studies were published by the same authors. The exclusion criteria were the following: 1) incomplete data; 2) highly obvious differences in the baseline characteristics of the case group and control group; 3) similar to a previously published study; and/or 4) ambiguous standards of diagnosis of the study subjects.

\section{Data extraction}

Two researchers independently performed data extraction from each eligible study by the application of the same data collection list. The data mainly consisted of the first author, submission year, country, ethnicity, language, disease, detection method, age, gender, study design and sample size, the number of cases and controls, etc. Disagreements in data extraction were resolved by a discussion among multiple researchers.

\section{Statistical analysis}

The STATA statistical software (Version 12.0, StataCorp. LP, College Station, TX, USA) was applied for the statistical analyses. To assess the differences in protein expression 
levels between the case group and control group, a standard mean difference (SMD) and 95\% confidence intervals $(95 \% \mathrm{CI})$ were calculated with the assistance of fixed- or random-effect models. A $Z$ test was used to assess the significance of the pooled effect size. We utilized the Cochran's $Q$-statistic ( $\mathrm{P}<0.05$ indicates significance) and the $I^{2}$ test to assess the heterogeneity among studies (Zintzaras and Ioannidis, 2005b). The random-effect model was utilized when evidence of significant heterogeneity was obtained $\left(\mathrm{P}<0.05\right.$ or $I^{2}$ test $\left.>50 \%\right)$; otherwise, the fixed-effect model was applied (Higgins and Thompson, 2002; Zintzaras and Ioannidis, 2005a). A sensitivity analysis was performed to examine the influence of each study on the overall results by removing the study and re-examining the results. In addition, a publication bias was tested with the Egger linear regression test $(\mathrm{P}<0.05$ indicated significance) together with asymmetry funnel plots (Song and Gilbody, 1998; Peters et al., 2006).

\section{RESULTS}

\section{Studies included}

A total of 1408 relevant studies were initially identified by an electronic database search and subsequent manual searching. We read the titles and abstracts and excluded 2 studies for duplicity; 5 studies for being letters, reviews, or meta-analyses; 5 studies for not examining humans; and 1290 studies for being unrelated. Furthermore, 92 studies were removed after reading the full text for not being case-control studies or not involving MMP1, MMP-2, or MMP-9 proteins and OA. Additionally, 4 studies were excluded for lacking sufficient information. Finally, a total of 10 case-control studies (Li et al., 2002; Xiao et al., 2002; Tchetverikov et al., 2004; Liu et al., 2007; Jiang, 2009; Driban et al., 2010; Rego-Perez et al., 2011; Heard et al., 2012; He and Shen, 2013; Liu and Wei, 2014) published between 2002 and 2014 were included in our meta-analysis. These studies included 753 subjects (458 patients with OA and 295 normal healthy controls). Six studies were done among Asian populations, and 4 studies involved Caucasians. The baseline characteristics of the studies included are listed in Tables 1-3 (Table 1: MMP-1; Table 2: MMP-2; Table 3: MMP-9).

\begin{tabular}{|c|c|c|c|c|c|c|c|c|c|c|c|}
\hline \multirow[t]{2}{*}{ First author } & \multirow[t]{2}{*}{ Country } & \multirow[t]{2}{*}{ Ethnicity } & \multicolumn{3}{|c|}{ Number } & \multicolumn{2}{|c|}{ Gender $(\mathrm{M} / \mathrm{F})$} & \multicolumn{2}{|c|}{ Age (years) } & \multirow[t]{2}{*}{ Study design } & \multirow[t]{2}{*}{ Sample } \\
\hline & & & Total & $\mathrm{OA}$ & Control & $\mathrm{OA}$ & Control & $\mathrm{OA}$ & Control & & \\
\hline $\operatorname{Li~DD~}(2002)^{\mathrm{a}}$ & China & Asians & 54 & 46 & 8 & $20 / 26$ & NR & $57.8(50-66)$ & NR & Non-RCT & Synovial fluid \\
\hline Li DD $(2002)^{b}$ & China & Asians & 66 & 46 & 20 & $20 / 26$ & NR & $57.8(50-66)$ & NR & Non-RCT & Serum \\
\hline Tchetverikov I (2004) $^{\mathrm{a}}$ & Netherlands & Caucasians & 28 & 13 & 15 & NR & $3 / 12$ & NR & NR & Non-RCT & Synovial fluid \\
\hline Tchetverikov I (2004) ${ }^{\mathrm{b}}$ & Netherlands & Caucasians & 28 & 13 & 15 & NR & $3 / 12$ & NR & NR & Non-RCT & Serum \\
\hline Liu Y (2007) & China & Asians & 50 & 33 & 17 & $15 / 18$ & $10 / 7$ & $71.3 \pm 11.9(40-92)$ & $50.2 \pm 25.4(14-78)$ & Non-RCT & Serum \\
\hline Rego-Perez I (2011) & Spain & Caucasians & 150 & 73 & 77 & $21 / 52$ & $38 / 39$ & $67.74 \pm 8.96(51-95)$ & $66.01 \pm 11.88(42-94)$ & Non-RCT & Serum \\
\hline Heard BJ (2012) & Canada & Caucasians & 42 & 17 & 25 & $8 / 9$ & $14 / 11$ & $42 \pm 10.77$ & $58.38 \pm 11.02$ & Non-RCT & Synovial fluid \\
\hline
\end{tabular}

MMP-1 = matrix metalloproteinase-1; $\mathrm{M}=$ male; $\mathrm{F}=$ female; $\mathrm{OA}=$ osteoarthritis; $\mathrm{NR}=$ not reported; Non-RCT $=$ non-randomized controlled trials; $\mathrm{a}=$ synovial fluid; $\mathrm{b}=$ serum. All data are reported as mean (range), means \pm standard deviation (range), or means \pm standard deviation.

\section{Expression of the MMP-1 protein}

The random-effect model was utilized to analyze for heterogeneity, which was positive $\left(I^{2}=60.9 \%, \mathrm{P}_{\mathrm{h}}=0.018\right)$. The meta-analysis results suggested that the MMP-1 
Table 2. Baseline characteristics of all of the studies on MMP-2 in this meta-analysis.

\begin{tabular}{|c|c|c|c|c|c|c|c|c|c|c|c|}
\hline \multirow[t]{2}{*}{ First author } & \multirow[t]{2}{*}{ Country } & \multirow[t]{2}{*}{ Ethnicity } & \multicolumn{3}{|c|}{ Number } & \multicolumn{2}{|c|}{ Gender $(\mathrm{M} / \mathrm{F})$} & \multicolumn{2}{|c|}{ Age (years) } & \multirow[t]{2}{*}{ Study design } & \multirow[t]{2}{*}{ Sample } \\
\hline & & & Total & $\mathrm{OA}$ & Control & $\mathrm{OA}$ & Control & $\mathrm{OA}$ & Control & & \\
\hline Tchetverikov I (2004) & Netherlands & Caucasians & 28 & 13 & 15 & NR & $3 / 12$ & NR & NR & Non-RCT & Synovial fluid \\
\hline Tchetverikov I (2004) & Netherlands & Caucasians & 28 & 13 & 15 & NR & $3 / 12$ & NR & NR & $\mathrm{RT}$ & Serum \\
\hline Liu Y (2007) & China & Asians & 50 & 33 & 17 & $15 / 18$ & $10 / 7$ & $71.3 \pm 11.9(40-92)$ & $50.2 \pm 25.4(14-78)$ & Non- & Serum \\
\hline Driban JB (2010) & USA & Caucasians & 16 & 8 & 8 & NR & NR & $65 \pm 6.0$ & $54 \pm 10$ & Non-RCT & Synovial fluid \\
\hline Heard BJ (2012) & Canada & Caucasians & 42 & 17 & 25 & $8 / 9$ & $14 / 11$ & $42 \pm 10.77$ & $58.38 \pm 11.02$ & Non-RCT & Synovial fluid \\
\hline He ZH (2013) & China & Asians & 62 & 52 & 10 & $25 / 27$ & $6 / 4$ & $52.6 \pm 5.7$ & $57.3 \pm 8.4$ & Non-RCT & Synovial fluid \\
\hline Liu Q (2014) & China & Asians & 80 & 34 & 46 & $16 / 18$ & $24 / 22$ & $61.5(46-77)$ & $41.5(36-47)$ & Non-RCT & Serum \\
\hline
\end{tabular}

MMP-2 = matrix metalloproteinase-2; $\mathrm{M}=$ male; $\mathrm{F}=$ female; $\mathrm{OA}=$ osteoarthritis; $\mathrm{NR}=$ not reported; Non-RCT $=$ non-randomized controlled trials; $\mathrm{a}=$ synovial fluid; $\mathrm{b}=$ serum. All data are reported as mean (range), means \pm standard deviation (range), or means \pm standard deviation.

Table 3. Baseline characteristics of all of the studies on MMP-9 in this meta-analysis.

\begin{tabular}{|c|c|c|c|c|c|c|c|c|c|c|c|}
\hline \multirow[t]{2}{*}{ First author } & \multirow[t]{2}{*}{ Country } & \multirow[t]{2}{*}{ Ethnicity } & \multicolumn{3}{|c|}{ Number } & \multicolumn{2}{|c|}{ Gender $(\mathrm{M} / \mathrm{F})$} & \multicolumn{2}{|c|}{ Age (years) } & \multirow[t]{2}{*}{ Study design } & \multirow[t]{2}{*}{ Sample } \\
\hline & & & Total & $\mathrm{OA}$ & Control & $\mathrm{OA}$ & Control & $\mathrm{OA}$ & Control & & \\
\hline Xiao XL (2002) & China & Asians & 61 & 31 & 30 & $14 / 17$ & $11 / 19$ & $45.5 \pm 6.0$ & $50 \pm 4.12$ & Non-RCT & Serum \\
\hline Tchetverikov I (2004) $)^{\mathrm{a}}$ & Netherlands & Caucasians & 28 & 13 & 15 & NR & $3 / 12$ & NR & NR & Non-RCT & Synovial fluid \\
\hline Tchetverikov I (2004) & Netherlands & Caucasians & 28 & 13 & 15 & NR & $3 / 12$ & NR & NR & Non-RCT & Serum \\
\hline Liu Y (2007) & China & Asians & 50 & 33 & 17 & $15 / 18$ & $10 / 7$ & $71.3 \pm 11.9(40-92)$ & $50.2 \pm 25.4(14-78)$ & Non-RCT & Serum \\
\hline Jiang TJ $(2009)^{\mathrm{a}}$ & China & Asians & 58 & 46 & 12 & $16 / 30$ & NR & $59(46-72)$ & $\mathrm{NR}$ & Non-RCT & Synovial fluid \\
\hline Jiang TJ $(2009)^{b}$ & China & Asians & 58 & 46 & 12 & $16 / 30$ & NR & $59(46-72)$ & NR & Non-RCT & Serum \\
\hline Heard BJ (2012) & Canada & Caucasians & 42 & 17 & 25 & $8 / 9$ & $14 / 11$ & $42 \pm 10.77$ & $58.38 \pm 11.02$ & Non-RCT & Synovial fluid \\
\hline He ZH (2013) & China & Asians & 62 & 52 & 10 & $25 / 27$ & $6 / 4$ & $52.6 \pm 5.7$ & $57.3 \pm 8.4$ & Non-RCT & Synovial fluid \\
\hline Liu Q (2014) & China & Asians & 80 & 34 & 46 & $16 / 18$ & $24 / 22$ & $61.5(46-77)$ & $41.5(36-47)$ & Non-RCT & Serum \\
\hline
\end{tabular}

MMP-9 = matrix metalloproteinase-9; $\mathrm{M}=$ male; $\mathrm{F}=$ female; $\mathrm{OA}=$ osteoarthritis; $\mathrm{NR}=$ not reported; Non-RCT $=$ non-randomized controlled trials; $\mathrm{a}=$ synovial fluid; $\mathrm{b}=$ serum. All data are reported as mean (range), means \pm standard deviation (range), or means \pm standard deviation.

protein expression levels were markedly and significantly higher in patients with OA than in normal people $(\mathrm{SMD}=0.48,95 \% \mathrm{CI}=0.12-0.83, \mathrm{P}=0.009)$ (Figure $1 \mathrm{~A})$. The ethnicity subgroup analysis found that MMP-1 protein expression levels were significantly increased in Asian patients with $\mathrm{OA}$ than in Asian controls $(\mathrm{SMD}=0.46,95 \% \mathrm{CI}=0.10-0.83, \mathrm{P}=0.014$ ). Surprisingly, the difference in MMP-1 protein expression levels between patients with OA and controls was not statistically significant in Caucasians $(\mathrm{SMD}=0.49,95 \% \mathrm{CI}=-0.13-1.10, \mathrm{P}$ $=0.121$ ) (Figure 2A). In addition, a subgroup analysis based on sample source revealed that the levels of expression of the MMP-1 protein in synovial joint fluid in patients with OA were obviously higher than those in the control group $(\mathrm{SMD}=1.03,95 \% \mathrm{CI}=0.61-1.46, \mathrm{P}<0.001)$, while the differences between the two groups in serum had no statistical significance ( $\mathrm{SMD}=$ $0.13,95 \% \mathrm{CI}=-0.10-0.37, \mathrm{P}=0.271$ ) (Figure $2 \mathrm{~B}$ ).

\section{Expression of the MMP-2 protein}

The random-effect model was utilized to test for the existence of heterogeneity $\left(I^{2}=\right.$ $\left.94.6 \%, \mathrm{P}_{\mathrm{h}}<0.001\right)$. The meta-analysis results showed significantly higher levels of MMP2 protein expression in patients with $\mathrm{OA}$ than in the control group $(\mathrm{SMD}=2.17,95 \% \mathrm{CI}=$ $0.80-3.53, \mathrm{P}=0.002$ ) (Figure 1B). The ethnicity subgroup analysis found that the levels of expression of the MMP-2 protein in Asians were higher in patients with OA than those in the control group $(\mathrm{SMD}=3.01,95 \% \mathrm{CI}=2.57-3.45, \mathrm{P}<0.001)$, but the differences in the levels of 
expression of MMP-1 and MMP-2 proteins in Caucasian patients with OA did not differ from controls $(\mathrm{SMD}=1.48,95 \% \mathrm{CI}=-0.37-3.32, \mathrm{P}=0.116$ ) (Figure $2 \mathrm{C})$. The subgroup analysis of sample source clarified that the levels of expression of the MMP-2 protein in serum in patients with OA were considerably and significantly higher than those in the control group (SMD = $2.04,95 \% \mathrm{CI}=0.47-3.61, \mathrm{P}=0.011)$, while the differences in the synovial joint fluid between the two groups were not significant $(\mathrm{SMD}=2.30,95 \% \mathrm{CI}=-0.20-4.80, \mathrm{P}=0.072)$ (Figure 2D).
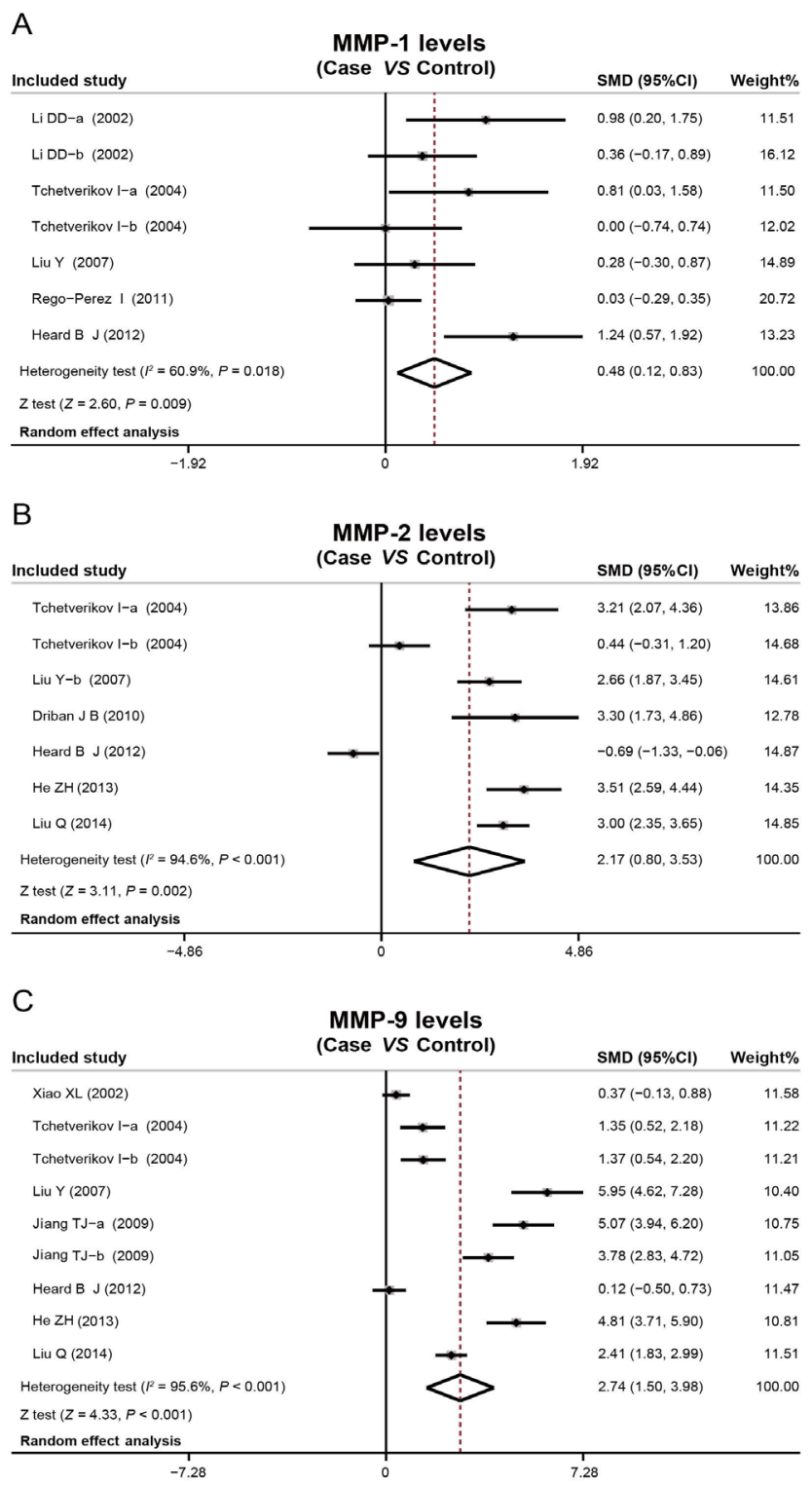

Figure 1. Forest plots of the associations between the protein levels of matrix metalloproteinase (MMP)-1, MMP2, and MMP-9 and osteoarthritis (A. MMP-1; B. MMP-2; C. MMP-9). 
A

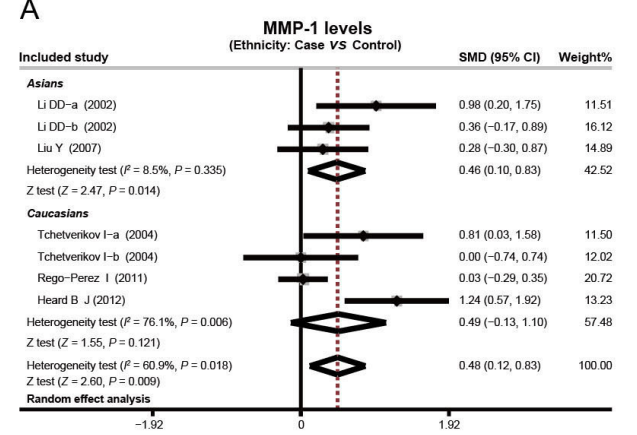

C

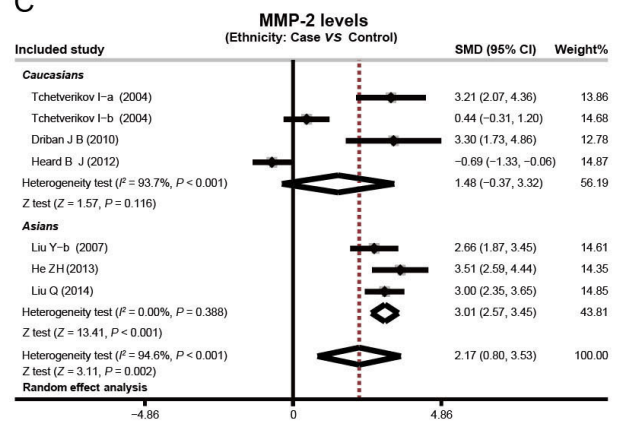

E
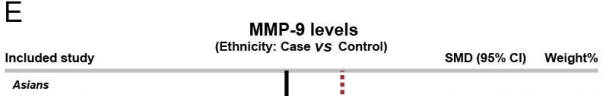

Xiao XL (2002)

Liu Y (2007)

Jiang TJ-a (2009)

Jiang TJ-b (2009)

He ZH (2013)

Liu $Q(2014)$
Heterogenenty test $\left(l^{2}=96.4 \%, P<0.001\right)$

Heterogeneity test $\left(r^{\prime}=96,4 \%\right.$
$Z$ test $(Z=4.10, P<0.001)$

Caucosians

Tchetereikov 1-a (2004)

Tchetererikov $1-b(20004)$
Heard B $\mathrm{B}(2012)$

Heterogeneity test $(P=75.6 \%, P=0.016)$

$Z$ test $(Z=2.02, P=0.043)$

Heterogeneity test $(P=95.6 \%, P<0.001)$

$Z$ test $(Z=4.33, P<0.00)$
Random effect analysis

Random effect analysis
B

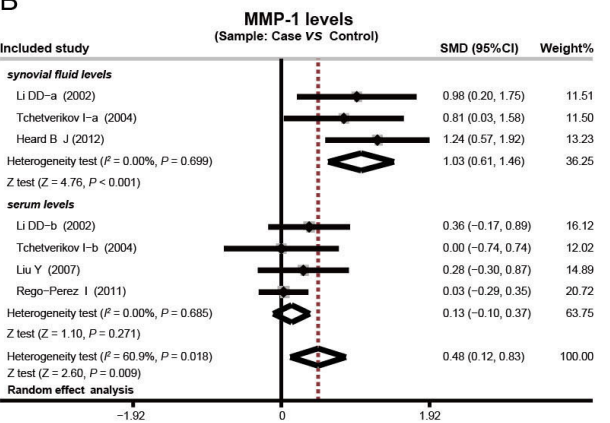

D

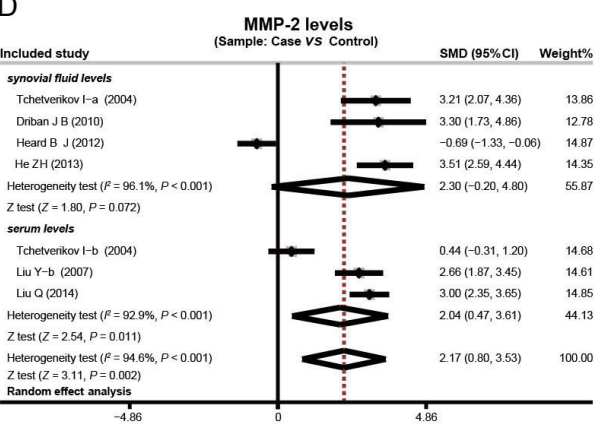

F

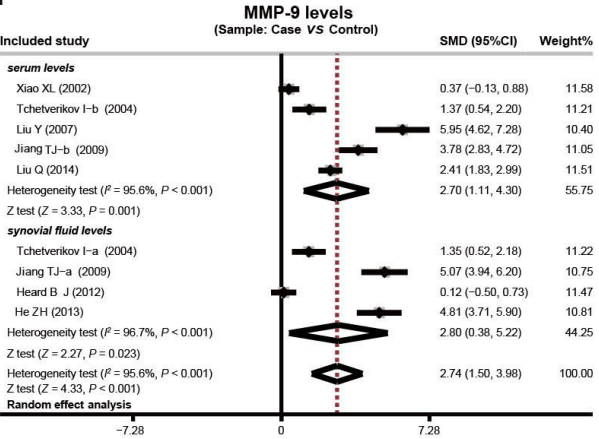

Figure 2. Forest plots of the association between the protein levels of MMP-1, MMP-2, and MMP-9 and osteoarthritis based on the ethnicity subgroups and sample source (A. and B. MMP-1; C. and D. MMP-2; E. and F. MMP-9).

\section{Expression of the MMP-9 protein}

The random-effect model was utilized to analyze for heterogeneity, and the test was positive $\left(I^{2}=95.6 \%, \mathrm{P}_{\mathrm{h}}<0.001\right)$. The meta-analysis results demonstrated that the levels of expression of the MMP-9 protein in patients with OA were substantially higher than those in the control group $(\mathrm{SMD}=2.74,95 \% \mathrm{CI}=1.50-3.98, \mathrm{P}<0.001)$ (Figure $1 \mathrm{C})$. The ethnicity subgroup analysis revealed that the levels of expression of the MMP-9 protein in patients with OA were significantly higher than those in the control group both in Asians $(\mathrm{SMD}=3.68,95 \% \mathrm{CI}=1.92$ 5.44, $\mathrm{P}<0.001)$ and Caucasians $(\mathrm{SMD}=0.91,95 \% \mathrm{CI}=0.03-1.79, \mathrm{P}=0.043)$ (Figure 2E). The 
subgroup analysis of sample source showed significantly higher levels of the MMP-9 protein in patients with $\mathrm{OA}$ than in the control group in both the joint synovial fluid $(\mathrm{SMD}=2.80,95 \% \mathrm{CI}$ $=0.38-5.22, \mathrm{P}=0.023)$ and serum $(\mathrm{SMD}=2.70,95 \% \mathrm{CI}=1.11-4.30, \mathrm{P}<0.001)$ (Figure $2 \mathrm{~F})$.

\section{Sensitivity analysis and publication bias}

A sensitivity analysis revealed that each study in our meta-analysis had no significant influence on the pooled SMDs of protein expression of MMP-1, MMP-2, and MMP-9 in the OA and nonOA groups (Figure 3). For the levels of expression of MMP-1 and MMP-2 proteins, Beggar funnel plots revealed some symmetry (Figure 4), and subsequent Egger's tests demonstrated the absence of publication bias in the studies that were included (MMP-1: $\mathrm{P}$ $=0.075$; MMP-2: $\mathrm{P}=0.282$ ). However, for the levels of expression of the MMP-9 protein, the funnel plots showed asymmetry and a subsequent Egger's linear regression analysis showed the existence of publication bias $(\mathrm{P}=0.005)$.
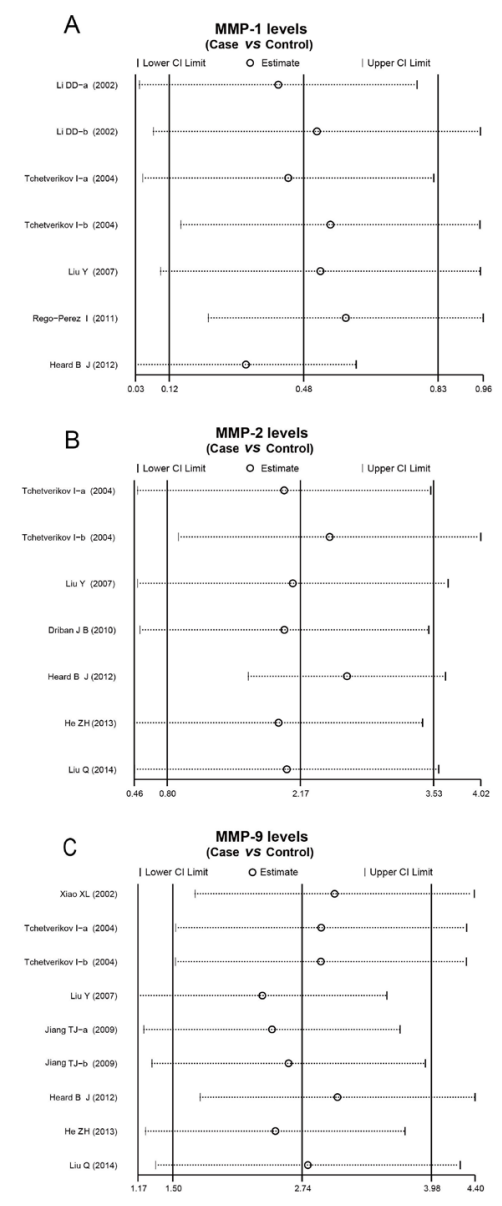

Figure 3. Sensitivity analyses of the association between the protein levels of MMP-1, MMP-2, and MMP-9 and osteoarthritis (A. MMP-1; B. MMP-2; C. MMP-9). 
A

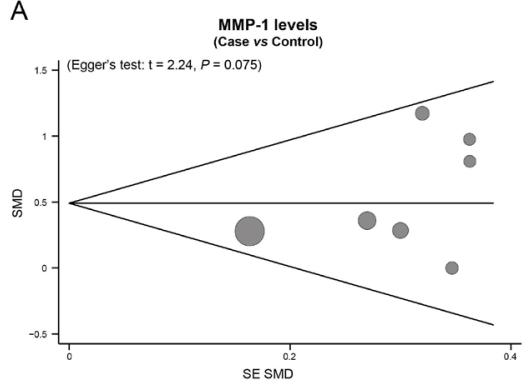

B

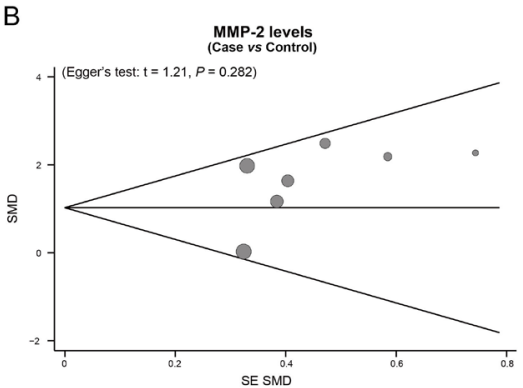

C

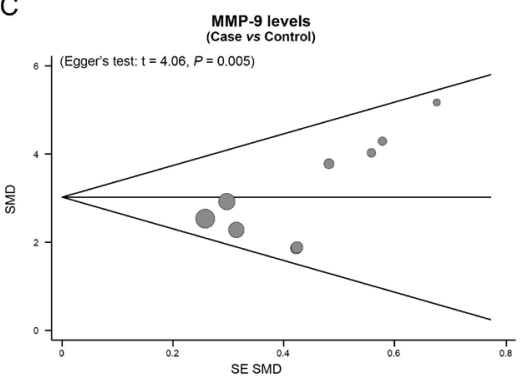

Figure 4. Funnel plot to demonstrate the risk of publication biases on the associations between the protein levels of MMP-1, MMP-2, and MMP-9 and osteoarthritis (A. MMP-1; B. MMP-2; C. MMP-9).

\section{DISCUSSION}

We conducted a comprehensive meta-analysis of selected published studies to investigate the association between the expressions of MMP-1, MMP-2, and MMP-9 proteins and the pathogenesis of OA. Our major finding was that the high protein levels of MMP-1, MMP-2, and MMP-9 proteins in OA might accelerate the pathogenesis of the disease, and this relationship could be neglected clinically. OA that results in stiffness and severe pain is frequently experienced aspect of the age-related skeletal disease. Characteristically, OA results in the progressive destruction of the articular cartilage of synovial joints and alterations within the adjacent bone (Chen et al., 2014). MMP-1, MMP-2, and MMP-9 proteins are very efficient in the turnover of the extracellular matrix because of their protease activities against their target proteins, and they contribute to the process of tumor invasion and metastasis in some diseases through tissue remodeling (Roy et al., 2009). Our findings illustrated that MMP-1, MMP-2, and MMP-9 protein levels were obviously higher in individuals with OA compared with those 
of normal people. MMP-1, which belongs to the collagenase subgroup within the MMP family, can degrade the triple helical chains of the type-II collagen of articular cartilage and exert an important influence on aberrant collagen turnover in OA (Wassilew et al., 2010). The collagen network of articular cartilage is mainly made of type-II collagen, which provides the articular cartilage with elasticity and deformability (Wu et al., 2008). Degradation of the collagen network considerably decreases the tissue elasticity and deformability, which is considered one of the earliest alterations in cartilage degeneration (Dejica et al., 2012). In addition, MMP-2 and MMP-9 proteins are gelatinases of the MMP family, and both have prominent roles in cancer setting (Galasso et al., 2012). MMP-2 and MMP-9 are secreted extracellularly, and these gelatinases cleave other targets, including growth factors, extracellular matrix, chemokines, and cytokines, which results in the release of these ligands, which in turn activate major signaling pathways that are involved in cell growth, invasion, inflammation, migration, and angiogenesis (Bauvois, 2012). Therefore, the increased protein levels of MMP-1, MMP2 , and MMP-9 in individuals with OA compared to normal people, which were shown in this meta-analysis, have significant biological consequences on the progression of the disease and important implications on the early diagnosis and treatment of OA.

Interestingly, we found unexpected differences in MMP-1, MMP-2, and MMP-9 proteins and the pathogenesis of OA when subgroups of ethnicity and sample source were analyzed. The ethnicity-based analysis showed that Asian patients with OA had significantly higher protein levels of MMP-1 and MMP-2 compared to the control group, while Caucasians did not exhibit such statistically significant differences in MMP-1 and MMP-2 protein levels between patients with $\mathrm{OA}$ and the control group. We suspect that genetic differences, geographical position, or limitations in the existing detection methods accounted for these observations, and we intend to follow up with further studies designed to address the ethnic differences. The subgroup analysis of the sample source found that protein expression of MMP-1 in the synovial joint fluid of patients with OA was substantially greater than that of the control group, while the difference in protein expression of MMP-1 in serum did not differ significantly between patients with OA and the control group. However, in serum, protein expression of MMP-2 was higher in patients with OA than in the control group, while the difference in protein expression of MMP-2 in the synovial joint fluid of patients with OA and the control group did not differ significantly. Furthermore, the ethnicity and sample source subgroup analyses revealed that protein expression of MMP-9 was apparently higher in both Asians and Caucasians and in joint synovial fluid and serum, which indicated that genetic differences or geographical position had little effect on the protein levels of MMP-9 in patients with OA.

There were a few limitations in the present meta-analysis. First, the sample sizes in the enrolled studies were comparatively small, and this may have resulted in a lack of confidence in the overall results. Second, the absence of some data in the published studies that were examined may limit the validity of our results. Finally, the inclusion and exclusion criteria may not have been complete. Thus, together with the retrieval and manual selection method, these limitations may have impacted the accuracy of the results by likely missing the more detailed studies.

In summary, this meta-analysis revealed that the protein levels of MMP-1, MMP-2, and MMP-9 may be associated with the pathogenesis of OA and that there were differences in the expression of the three proteins in the synovial joint fluid and serum. In addition, we 
identified important differences in the pattern of MMP expression among Asian and Caucasian patients with OA. Thus, further detailed studies are warranted to understand the roles of the MMP-1, MMP-2, and MMP-9 proteins in the pathogenesis of OA as a prelude to clinical application of the knowledge gained.

\section{Conflicts of interest}

The authors declare no conflict of interest.

\section{ACKNOWLEDGMENTS}

We are grateful to the expert reviewers of this paper for their helpful comments.

\section{REFERENCES}

Bauvois B (2012). New facets of matrix metalloproteinases MMP-2 and MMP-9 as cell surface transducers: outside-in signaling and relationship to tumor progression. Biochim. Biophys. Acta 1825: 29-36.

Bennell KL and Hinman RS (2011). A review of the clinical evidence for exercise in osteoarthritis of the hip and knee. $J$. Sci. Med. Sport 14: 4-9.

Bijlsma JW, Berenbaum F and Lafeber FP (2011). Osteoarthritis: an update with relevance for clinical practice. Lancet 377: 2115-2126.

Blagojevic M, Jinks C, Jeffery A and Jordan KP (2010). Risk factors for onset of osteoarthritis of the knee in older adults: a systematic review and meta-analysis. Osteoarthritis Cartilage 18: 24-33.

Bourboulia D and Stetler-Stevenson WG (2010). Matrix metalloproteinases (MMPs) and tissue inhibitors of metalloproteinases (TIMPs): Positive and negative regulators in tumor cell adhesion. Semin. Cancer Biol. 20: 161-168.

Chen YJ, Tsai KS, Chan DC, Lan KC, et al. (2014). Honokiol, a low molecular weight natural product, prevents inflammatory response and cartilage matrix degradation in human osteoarthritis chondrocytes. J. Orthop. Res. 32: 573-580.

De Groef L, Van Hove I, Dekeyster E, Stalmans I, et al. (2014). MMPs in the neuroretina and optic nerve: modulators of glaucoma pathogenesis and repair? Invest. Ophthalmol. Vis. Sci. 55: 1953-1964.

Dejica VM, Mort JS, Laverty S, Antoniou J, et al. (2012). Increased type II collagen cleavage by cathepsin K and collagenase activities with aging and osteoarthritis in human articular cartilage. Arthritis Res. Ther. 14: R113.

Dreier R (2010). Hypertrophic differentiation of chondrocytes in osteoarthritis: the developmental aspect of degenerative joint disorders. Arthritis Res. Ther. 12: 216.

Driban JB, Balasubramanian E, Amin M, Sitler MR, et al. (2010). The potential of multiple synovial-fluid proteinconcentration analyses in the assessment of knee osteoarthritis. J. Sport. Rehabil. 19: 411-421.

Ekman EF, Gimbel JS, Bello AE, Smith MD, et al. (2014). Efficacy and Safety of Intravenous Tanezumab for the Symptomatic Treatment of Osteoarthritis: 2 Randomized Controlled Trials versus Naproxen. J. Rheumatol. 41: 2249-2259.

Galasso O, Familiari F, De Gori M and Gasparini G (2012). Recent findings on the role of gelatinases (matrix metalloproteinase-2 and -9) in osteoarthritis. Adv. Orthop. 2012: 834208.

He ZH and Shen JW (2013). The value of MMP-2, MMP-3, MMP-9 and TIMP-1 levels in the evaluation of knee joint osteoarthritis. Chongqing Med. 32: 3872-3874.

Heard BJ, Martin L, Rattner JB, Frank CB, et al. (2012). Matrix metalloproteinase protein expression profiles cannot distinguish between normal and early osteoarthritic synovial fluid. BMC Musculoskelet. Disord. 13: 126.

Hemmann S, Graf J, Roderfeld M and Roeb E (2007). Expression of MMPs and TIMPs in liver fibrosis - a systematic review with special emphasis on anti-fibrotic strategies. J. Hepatol. 46: 955-975.

Higgins JP and Thompson SG (2002). Quantifying heterogeneity in a meta-analysis. Stat. Med. 21: 1539-1558.

Hughes BG and Schulz R (2014). Targeting MMP-2 to treat ischemic heart injury. Basic Res. Cardiol. 109: 424.

Jackson MT, Moradi B, Smith MM, Jackson CJ, et al. (2014). Activation of matrix metalloproteinases 2, 9, and 13 by activated protein C in human osteoarthritic cartilage chondrocytes. Arthritis Rheumatol. 66: 1525-1536.

Jiang TJ (2009). Detection of levels of serum and knee synovial fluid MMP-9 and TNF- $\alpha$ in patients with osteoarthritis and 
its clinical significance. Med. J. Nat. Defending Forces Southwest China 380-382.

Lane NE, Brandt K, Hawker G, Peeva E, et al. (2011). OARSI-FDA initiative: defining the disease state of osteoarthritis. Osteoarthritis Cartilage 19: 478-482.

Lepetsos P, Pampanos A, Kanavakis E, Tzetis M, et al. (2014). Association of MMP-1 -1607 1G/2G (rs1799750) polymorphism with primary knee osteoarthritis in the Greek population. J. Orthop. Res. 32: 1155-1160.

Li DD, Wang Y, Yu SL, Li SM, et al. (2002). Serum and synovial fluid levels of matrix metalloproteinases and its tissue inhibitor in patients with osteoarthritis. China J. Orthopaedics Traumatol. 9-12.

Liu Q and Wei JB (2014). Evaluation of MMP-2 and MMP-9 in diagnosis of rheumatoid arthritis by ROC curve. Chin. J. Health Lab. Technol. 24: 531-533.

Liu Y, Guo CA and Chen ZR (2007). Matrix metalloproteinase-1, 2, 3 and 9 levels in serum and synovial fluid of patients with osteoarthritis and rheumatoid arthritis. Shanghai Med. J. 30: 50-52.

Lukaszewicz-Zajac M, Mroczko B, Kornhuber J and Lewczuk P (2014). Matrix metalloproteinases (MMPs) and their tissue inhibitors (TIMPs) in the tumors of central nervous system (CNS). J. Neural Transm. 121: 469-477.

Murphy G and Nagase H (2008). Reappraising metalloproteinases in rheumatoid arthritis and osteoarthritis: destruction or repair? Nat. Clin. Pract. Rheumatol. 4: 128-135.

Peters JL, Sutton AJ, Jones DR, Abrams KR, et al. (2006). Comparison of two methods to detect publication bias in metaanalysis. JAMA 295: 676-680.

Rego-Perez I, Fernandez-Moreno M, Deberg M, Pertega S, et al. (2011). Mitochondrial DNA haplogroups and serum levels of proteolytic enzymes in patients with osteoarthritis. Ann. Rheum. Dis. 70: 646-652.

Roy R, Yang J and Moses MA (2009). Matrix metalloproteinases as novel biomarkers and potential therapeutic targets in human cancer. J. Clin. Oncol. 27: 5287-5297.

Salgame P (2011). MMPs in tuberculosis: granuloma creators and tissue destroyers. J. Clin. Invest. 121: 1686-1688.

Song F and Gilbody S (1998). Bias in meta-analysis detected by a simple, graphical test. Increase in studies of publication bias coincided with increasing use of meta-analysis. BMJ 316: 471.

Tchetverikov I, Ronday HK, Van El B, Kiers GH, et al. (2004). MMP profile in paired serum and synovial fluid samples of patients with rheumatoid arthritis. Ann. Rheum. Dis. 63: 881-883.

Tio L, Martel-Pelletier J, Pelletier JP, Bishop PN, et al. (2014). Characterization of opticin digestion by proteases involved in osteoarthritis development. Joint Bone Spine 81: 137-141.

Wassilew GI, Lehnigk U, Duda GN, Taylor WR, et al. (2010). The expression of proinflammatory cytokines and matrix metalloproteinases in the synovial membranes of patients with osteoarthritis compared with traumatic knee disorders. Arthroscopy 26: 1096-1104.

Wu H, Du J and Zheng Q (2008). Expression of MMP-1 in cartilage and synovium of experimentally induced rabbit ACLT traumatic osteoarthritis: immunohistochemical study. Rheumatol. Int. 29: 31-36.

Xiao XL, Liang XP, Feng XX, Sun BD, et al. (2002). The expression and clinical significance of TGF- $\beta$ and MMP in patients with osteoarthritis. J. Clin. Int. Med. 19: 434-434.

Xu L, Servais J, Polur I, Kim D, et al. (2010). Attenuation of osteoarthritis progression by reduction of discoidin domain receptor 2 in mice. Arthritis Rheum. 62: 2736-2744.

Xue M, McKelvey K, Shen K, Minhas N, et al. (2014). Endogenous MMP-9 and not MMP-2 promotes rheumatoid synovial fibroblast survival, inflammation and cartilage degradation. Rheumatology 53: 2270-2279.

Zintzaras E and Ioannidis JP (2005a). Heterogeneity testing in meta-analysis of genome searches. Genet. Epidemiol. 28: 123-137.

Zintzaras E and Ioannidis JP (2005b). HEGESMA: genome search meta-analysis and heterogeneity testing. Bioinformatics 21: $3672-3673$. 